\title{
Critical Factors in the Anodic Formation of Extremely Ordered Titania Nanocavities
}

\author{
J. E. Yoo ${ }^{1}{ }^{1}$ and P. Schmuki $\oplus^{1,2, *, z}$ \\ ${ }^{1}$ Department of Materials Science, Institute for Surface Science and Corrosion WW4-LKO, Friedrich-Alexander \\ University, D-91058 Erlangen, Germany \\ ${ }^{2}$ Chemistry Department, Faculty of Sciences, King Abdulaziz University, 80203 Jeddah, Saudi Arabia
}

\begin{abstract}
In the present work, we discuss the formation of a highly ordered form of $\mathrm{TiO}_{2}$ nanotubes (U-tubes) which are grown by anodizing Ti metal in a concentrated $\mathrm{HF} / \mathrm{H}_{3} \mathrm{PO}_{4}$ electrolyte. The crucial parameters determining geometry and order of the tubes (such as, temperature, applied voltage, concentration of HF, and anodizing time) are investigated and discussed. Under optimized conditions, not only very high degree of order, but also a perfectly open tube top morphology is obtained. The amorphous titania tubes (cavities) consist of a phosphate rich inner layer and a fluoride rich outer layer. Thermal crystallization of these short amorphous cavities to anatase/rutile at temperatures $\left(>400^{\circ} \mathrm{C}\right)$ in air leads to partial oxidation of the underneath metal - this and the short length of the tubes, usually around $200 \mathrm{~nm}$, pose challenges for potential photoelectrochemical applications. However, the limited tube length can be overcome by a double anodizing technique. The extremely high order and unique nature of these types of self-ordered tubes allows for unprecedented control and enables various uses of the tubes.

(C) The Author(s) 2019. Published by ECS. This is an open access article distributed under the terms of the Creative Commons Attribution 4.0 License (CC BY, http://creativecommons.org/licenses/by/4.0/), which permits unrestricted reuse of the work in any medium, provided the original work is properly cited. [DOI: 10.1149/2.0381911jes]

(cc) BY
\end{abstract}

Manuscript submitted March 4, 2019; revised manuscript received May 15, 2019. Published June 12, 2019. This paper is part of the JES Focus Issue on Advanced Techniques in Corrosion Science in Memory of Hugh Isaacs.

Over the past decades, nanostructured $\mathrm{TiO}_{2}$ and particularly selfordered anodic $\mathrm{TiO}_{2}$ nanotubes have attracted wide scientific and technological interest. ${ }^{1-11}$ The main reason for this interest is that these nanotubes not only provide a large active surface area but also a highly defined electrode geometry that is beneficial for a wide range of applications, e.g. in photocatalytic self-cleaning or $\mathrm{H}_{2}$ generation, electrochromic devices, biomedical coatings, sensors, and photovoltaics. ${ }^{12,13}$

In 1984, Assefpour-Dezfuly et al. grew the first self-ordered $\mathrm{TiO}_{2}$ nanostructures by anodizing $\mathrm{Ti}$ in a acidic fluoride-containing electrolyte; however, only a few hundred nanometers of layer thickness with a high degree of disorder could be obtained. ${ }^{14}$ These structures turned out to have a tubular shape and were optimized in the following years through the second generation formed in aqueous neutral electrolytes. ${ }^{15}$ The third generation of $\mathrm{TiO}_{2} \mathrm{NTs}$ was formed in organic electrolytes and showed a smooth and controllable geometry. ${ }^{16}$ Today, the most commonly used electrolytes for electrochemical growth of $\mathrm{TiO}_{2}$ nanotubes are based on $\mathrm{NH}_{4} \mathrm{~F}$ or $\mathrm{HF}$ in water/ethylene glycol (EG) or water/glycerol electrolytes. ${ }^{17}$ In these electrolytes, generally the voltage used for anodizing Ti determines the tube diameters, and the anodization time does not only affect the tube length but also the top morphology of the tubes.

Generally, for the $\mathrm{TiO}_{2}$ NTs grown in organic electrolytes, inhomogeneous layers on the top (i.e. initiation layers or so-called nanograss) are observed. Moreover, these tubes show a core-shell structure with an inner carbon rich (contamination) layer. One promising method for obtaining open top tube structures for $\mathrm{TiO}_{2} \mathrm{NTs}$ is based on the classical approach growing ordered porous alumina. ${ }^{18,19}$

The tubes grow usually as amorphous $\mathrm{TiO}_{2}$ with an outer fluoride layer that originates from growth under high field conditions. ${ }^{20,21} \mathrm{In}$ order to use the tubes in many photoelectrochemical applications, they are usually air annealed to anatase or anatase/rutile mixtures (in this process usually also the fluoride layer is lost). ${ }^{22}$ While an adequate annealing not only leads to crystallization of the tubes - including highly effective twinned anatase structures - also the concomitant oxidation of the Ti substrate needs to be considered ${ }^{23}$ (we will address this also in this work).

In the present work we discuss critical parameters in the formation of extremely ordered $\mathrm{TiO}_{2}$ nanotube structures that form as nanocavi-

*Electrochemical Society Fellow.

${ }^{\text {zE}}$-mail: schmuki@ww.uni-erlangen.de ties in electrolytes consisting of highly concentrated $\mathrm{HF}$ and o- $\mathrm{H}_{3} \mathrm{PO}_{4}$. This form of tubes, also referred to as "U-tubes", show the highest degree of self-ordering of all nanotubes, if not an imprinting approach is used, as recently described in literature. ${ }^{24}$ Moreover, these tubes do not have the drawbacks of tubes that were formed from organic electrolytes (closed tube mouth, "grass", C-contamination layer).

\section{Experimental}

In order to fabricate anodic $\mathrm{TiO}_{2}$ layers, Ti foils $(0.125 \mathrm{~mm}$ thickness, $99.6 \%$ purity Advent, $15 \times 30 \mathrm{~mm}$ ) were used as anode material. The Ti foils were degreased by sonication in acetone, ethanol, and deionized (DI) water for $20 \mathrm{~min}$, respectively, and dried in a stream of nitrogen. The electrolyte was prepared with melted $\mathrm{o}-\mathrm{H}_{3} \mathrm{PO}_{4}$ which was mixed with $3 \mathrm{M}$ of HF (40\% purity, Sigma-Aldrich). The electrolyte was held at $100^{\circ} \mathrm{C}$ for $30 \mathrm{~min}$ to reduce the water content, and the temperature was kept at $100^{\circ} \mathrm{C}$ during anodization.

For the growth of optimized ordered $\mathrm{TiO}_{2}$ nanotube arrays, anodization was carried out under various conditions, such as applied potential: $2-40 \mathrm{~V}$ by a power supply (VLP-2403 pro, Voltcraft), temperature: $80-120^{\circ} \mathrm{C}$ on hot plate (C-MAG HS 7 digital, IKA), and time: $10 \mathrm{~min}-24 \mathrm{~h}$. After the anodization, the nanotube layers were rinsed with ethanol and dried in an $\mathrm{N}_{2}$ stream. During anodization, current density was recorded by a Keithley multimeter connected to a computer through a General Purpose Interface Bus (GPIB) card.

Double anodization was performed to enlarge the thickness of the U-tube layers. The $1^{\text {st }}$ step was carried out in $3 \mathrm{M} \mathrm{HF}$ in $\mathrm{o}-\mathrm{H}_{3} \mathrm{PO}_{4}$ at $2-15 \mathrm{~V}$ for $2-12 \mathrm{~h}$, and then the anodic NTs were rinsed with ethanol. The $2^{\text {nd }}$ step was performed at $20-60 \mathrm{~V}$ for $2-10 \mathrm{~min}$ in an organic electrolyte consisting of $0.15 \mathrm{M} \mathrm{NH}_{4} \mathrm{~F}$ and $3 \mathrm{vol} \%$ of $\mathrm{H}_{2} \mathrm{O}$. The potential and anodizing time of the $2^{\text {nd }}$ step were optimized for the diameter and length of nanotubes from the $1^{\text {st }}$ step; i.e. $2 \mathrm{~V} 12 \mathrm{~h} / /$ $20 \mathrm{~V} 10 \mathrm{~min}, 5 \mathrm{~V} 5 \mathrm{~h} / / 30 \mathrm{~V} 5 \mathrm{~min}$, and $15 \mathrm{~V} 2 \mathrm{~h} / / 60 \mathrm{~V} 2 \mathrm{~min}$.

To fabricate replica structures, $\mathrm{TiO}_{2}$ nanotubes were filled with molten polystyrene (PS, Sigma Aldrich, Mw 35,000) by heating at $110^{\circ} \mathrm{C}$. The $\mathrm{Ti} / \mathrm{TiO}_{2}$ substrates were removed from the samples by immersing the samples in $1 \mathrm{M} \mathrm{HF}$ aqueous solution for $5 \mathrm{~h}$.

A field-emission scanning electron microscope (Hitachi FE-SEM S4800) was used for morphological characterization at the same acceleration voltage. Most of the cross-sectional images were obtained on mechanically scratched samples. In addition, cross-sections of tubes were obtained by ion-milling (IM IM4000, Hitachi). 

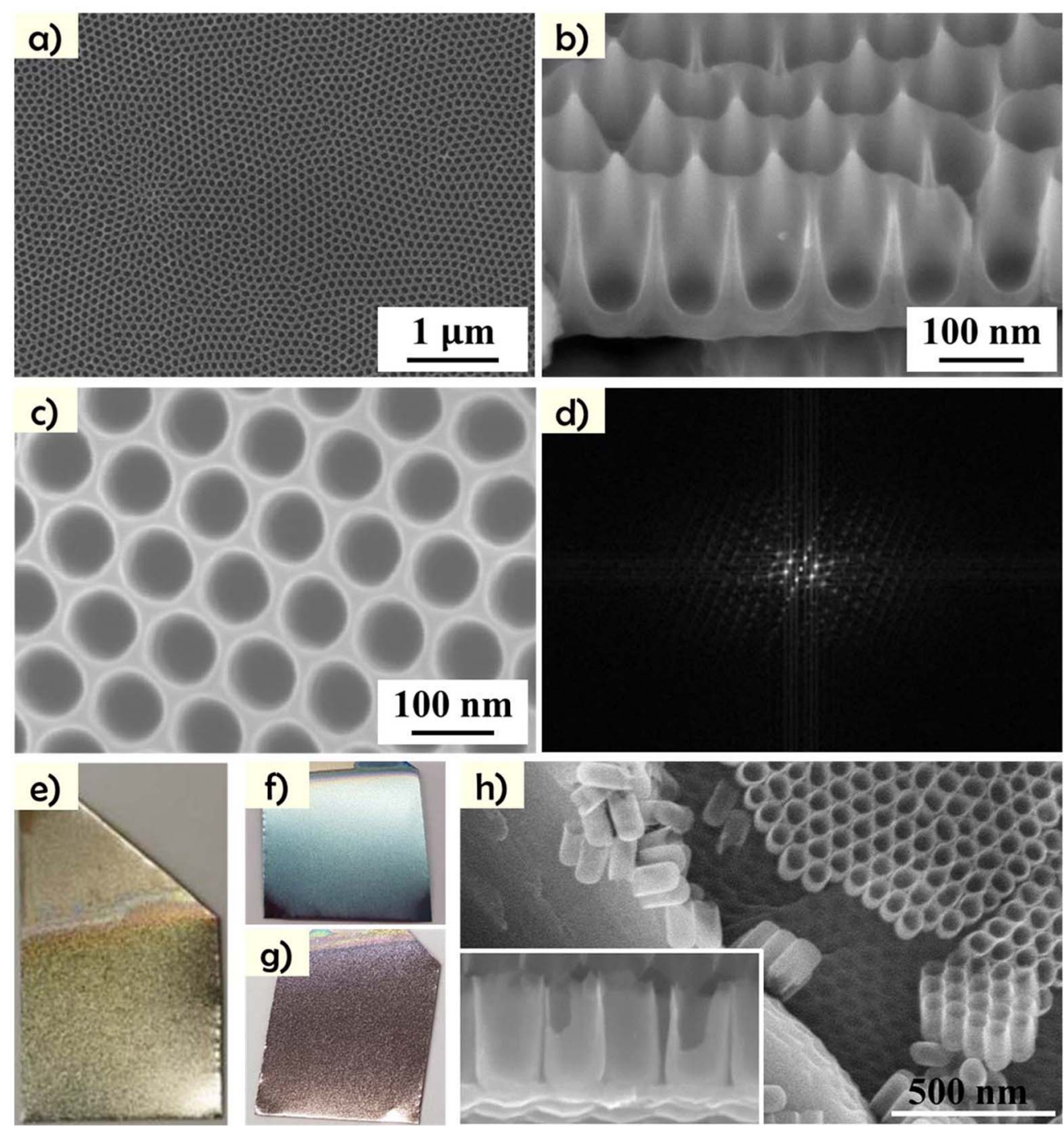

Figure 1. a $\sim$ c) SEM images of highly ordered $\mathrm{TiO}_{2}$ nanotube arrays (U-tubes) prepared in $3 \mathrm{M} \mathrm{HF} / \mathrm{H}_{3} \mathrm{PO}_{4}$ solution at $15 \mathrm{~V}$ and $100^{\circ} \mathrm{C}$ for $2 \mathrm{~h}$. Ti foil sheet and Pt sheet were used as working and counter electrode respectively. d) Fast Fourier Transform (FFT) conversion of Figure 1c. e g) Optical pictures of as-formed U-tubes on Ti substrate which were anodized in $3 \mathrm{M} \mathrm{HF} / \mathrm{H}_{3} \mathrm{PO}_{4}$ solution at $15 \mathrm{~V}$ and $100^{\circ} \mathrm{C} \mathrm{e}$ ) for $\left.2 \mathrm{~h}, \mathrm{f}\right) 10 \mathrm{~min}$, and g) $5 \mathrm{~h}$. f) SEM image of as-formed U-tubes (anodized in $3 \mathrm{M} \mathrm{HF} / \mathrm{H}_{3} \mathrm{PO}_{4}$ solution at $15 \mathrm{~V}$ and $100^{\circ} \mathrm{C}$ for $2 \mathrm{~h}$ ) after exposure to water.

XRD analysis (X'pert Philips MPD with a Panalytical X'celerator detector) using graphite monochromatized $\mathrm{Cu} \mathrm{K} \alpha$ radiation (wavelength $1.54056 \AA$ ) was used for determining the crystallographic structure of the samples.

The photoelectrochemical water splitting experiments were carried out under simulated AM $1.5\left(100 \mathrm{~mW} \mathrm{~cm}^{-2}\right)$ illumination provided by a solar simulator ( $300 \mathrm{~W}$ Xe with optical filter, Solarlight; RT) in $1 \mathrm{M} \mathrm{KOH}$ solution. Photocurrent versus voltage (I-V) characteristics were recorded by scanning the potential from -0.7 to $+0.5 \mathrm{~V}$ (vs. $\mathrm{Ag} / \mathrm{AgCl}(3 \mathrm{M} \mathrm{KCl}))$ with a scan rate of $1 \mathrm{mV} \mathrm{s}^{-1}$ using a Jaissle IMP $88 \mathrm{PC}$ potentiostat.

Electrochemical impedance spectroscopy (EIS) measurements were performed in the frequency range of $100 \mathrm{kHz}$ to $10 \mathrm{mHz}$ with an AC amplitude of $10 \mathrm{mV}$, at open circuit potential in $0.1 \mathrm{M} \mathrm{Na}_{2} \mathrm{SO}_{4}$ solution, using a Zahner IM6 setup (Zahner Elektrik, Kronach, Germany).

\section{Results and Discussion}

Figure 1 gives an overview of the morphology and typical features of highly ordered $\mathrm{TiO}_{2}$ nanocavities (U-tubes) grown at $15 \mathrm{~V}$ for $2 \mathrm{~h}$ in a mixture of $3 \mathrm{M} \mathrm{HF}$ and o- $\mathrm{H}_{3} \mathrm{PO}_{4}$ at $100^{\circ} \mathrm{C}$. From the $\mathrm{SEM}$ top views (in Figures 1a, 1c) it is clear that these tube layers show an extremely well ordered arrangement. Figure 1d represents a fast Fourier trans- form (FFT) of Figure 1c; the occurrence of regular "reflection peaks" illustrates the high degree of order present in this structure (classic nanotube layer top views do not show any well-defined FFT pattern, as they do not provide a sufficient degree of order). The nanotube layer presented in Figure 1 is the result of optimized anodization conditions. The tubes show an extremely uniform ordering, with a precise homogeneous diameter, size and layer thickness over a wide range of the anode surface (Figures 1a 1c). The cross sectional image in Figure 1b shows the tubes to be $\sim 200 \mathrm{~nm}$ long with a U-shaped profile. Importantly, the layers are free from any initiation layer and/or nanograss structures often observed for other type of nanotubes, and show a uniform and open tube top mouth. In view of various applications of these tube layers, this morphological feature is very important, as it allows for the deposition of secondary materials, or the use of the layer as a template. ${ }^{25-27}$

The image of the electrode after anodization (Figure 1e) shows interference colors with a color-homogeneity and shine; that is typical for these highly organized $\mathrm{TiO}_{2}$ NTs. Thin anodic layers exhibit various interference colors that vary with layer thickness; blue for $110 \mathrm{~nm}$ (Figure 1f), green for 180 and light pink for $230 \mathrm{~nm}$ (Figure 1g). The tube layer in Figure 1 is approximately $200 \mathrm{~nm}$ thick, corresponding well to the green-yellow color. It should be noted that a post treatment after anodizing is of utmost importance. In order to obtain the intact layer 

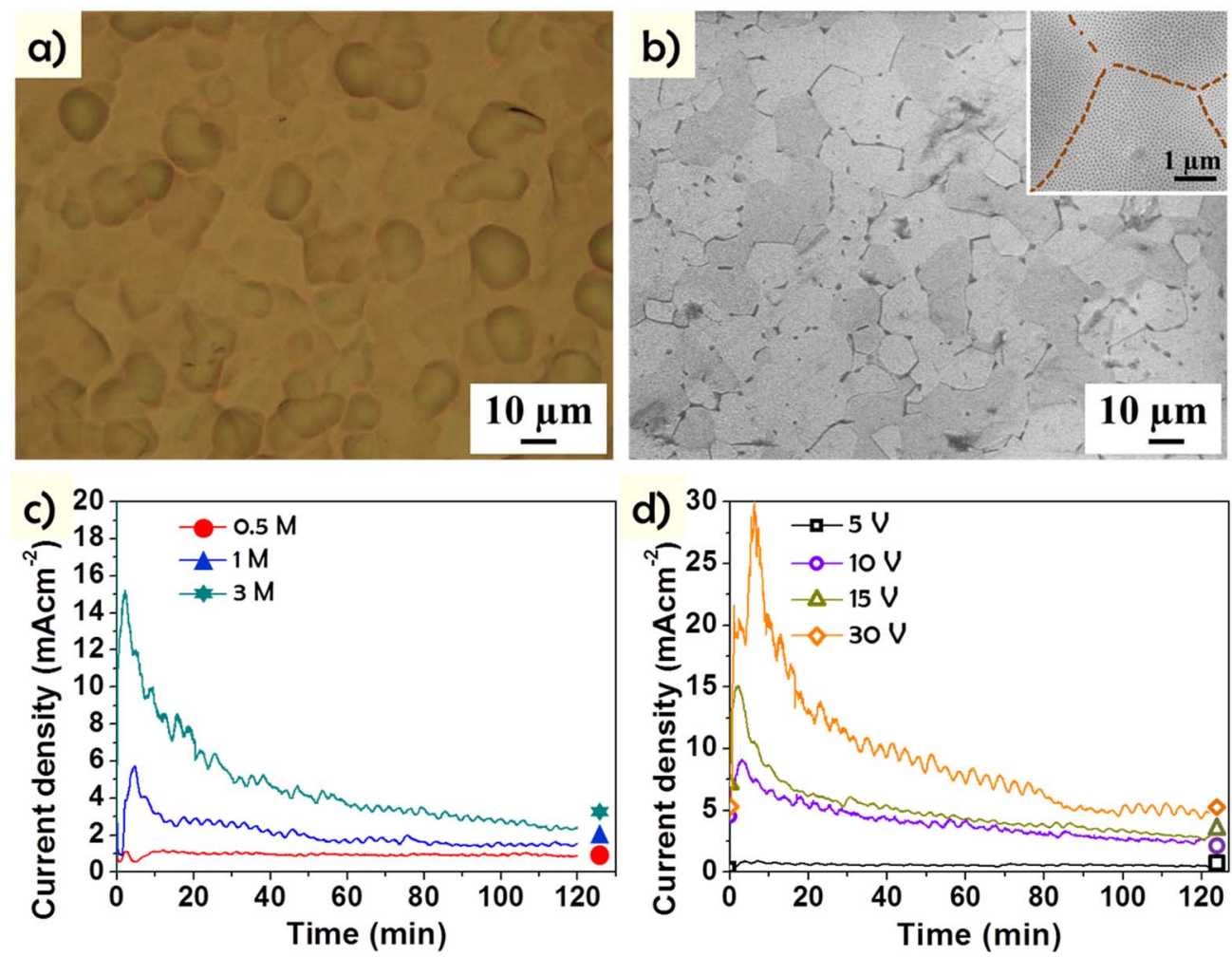

Figure 2. a) Optical microscope image of as-formed U-tubes (anodized in $3 \mathrm{M} \mathrm{HF} / \mathrm{H}_{3} \mathrm{PO}_{4}$ at $100^{\circ} \mathrm{C}$ and $15 \mathrm{~V}$ for $2 \mathrm{~h}$ ). b) SEM image of Ti substrate. The grains were revealed after etching Ti foil in $\mathrm{H}_{2} \mathrm{O}_{2}$ solution (insert: zoomed out SEM image of U-tubes). c $\sim \mathrm{d}$ ) I-t curves during anodizing $\mathrm{Ti}$ in $\mathrm{HF} / \mathrm{H}_{3} \mathrm{PO} \mathrm{P}_{4}$ electrolyte at $100^{\circ} \mathrm{C}$ for $2 \mathrm{~h}$; c) with different concentrations of $\mathrm{HF} ; \mathrm{d}$ ) at different applied potentials.

morphology shown in Figure 1, after formation the layer needs to be immersed directly in ethanol for overnight and then dried in $\mathrm{N}_{2}$ steam. If instead the formed nanotube layers are immersed in water, the layers can be further etched and the nanotubes can be easily separated (SEM images in Figure 1h). Controlled water treatment can thin down the wall of nanotubes; they become transparent in SEM images taken at the same acceleration voltage giving them a ghost-tube appearance, but the well-aligned ordering of nanotubes can still be retained.

Figure 2 shows a mildly crystallographically etched electrode surface after nanotubes are grown, (Figure 2a) in an optical microscope image, and (Figure 2b) in a SEM image. From both images substrate grains become visible, the size of the Ti grains is approximately 10 $20 \mu \mathrm{m}$. While within a grain highly ordered tubes are formed, from high-resolution SEM images at the grain boundaries it is apparent that the nanotubes grow with a change in their alignment, i.e. they show a different registry on different grains. Recently, this correlation of grain orientation between $\mathrm{TiO}_{2} \mathrm{NTs}$ and $\mathrm{Ti}$ substrate has been examined by polycrystalline $\mathrm{Ti}$ foils anodized in various aqueous and organic solutions. ${ }^{28}$ I.e. also in our electrolyte, the formation of Utubes is dependent on the orientation of the underlying $\mathrm{Ti}$ substrate. During the formation of the tubes, two key parameters are the HF concentration and the anodizing voltage. This is also apparent from the current density vs. time (I-t curves) in Figures $2 \mathrm{c} \sim 2 \mathrm{~d}$ for different $\mathrm{HF}$ concentrations and different anodizing voltages. All I-t curves show typical characteristics for passivation and self-organization: First, the current increases and then drops exponentially with increasing layer thickness, as an initial oxide layer forms that hampers ion transfer. Then tube growth starts and is in competition with oxide dissolution the situation levels off to a steady current flow, where tube formation and dissolution are in dynamic equilibrium. ${ }^{9,15,29}$ Clearly, the overall current densities increase with increasing HF concentration or higher anodizing potential. The effects become more apparent when the conditions are harsher. At the same time, order increases (as shown in Figure 3 and Figure 4).
Figures 3a 3e illustrates the effect of HF concentrations on the diameter and morphology of U-tubes; the anodization was carried out at $100^{\circ} \mathrm{C}$ for $2 \mathrm{~h}$. From the SEM images it is evident that in every case the thickness of tube layer is around $200 \mathrm{~nm}$ and all of the tubes have an open top (no initiation layer, no nanograss). The top and cross sectional views of $\mathrm{TiO}_{2}$ NTs grown in the low concentrated HF electrolyte (e.g. 0.2 and $0.5 \mathrm{M}$ ) obviously show an inhomogeneous arrangement of nanotubes. For $\mathrm{TiO}_{2} \mathrm{NTs}$ formed in high concentrated HF solutions ( 1 and $3 \mathrm{M}$ ), the nanotube morphologies show a high homogeneity and extreme ordering over a large surface area; this not only in the top view but also in cross-sectional images. From these observations it is evident that a high electric field is essential to achieve extremely high ordering of $\mathrm{TiO}_{2}$ nanotube arrays. However, if even more concentrated HF solutions are used $(>5 \mathrm{M})$, an electropolished surface instead of nanotubular structures is obtained (Figure 3e). This is in line with work of Ono et al. who reported that mainly the effective "electric field" influences self-ordering. ${ }^{30}$ Ono et al. showed this for porous alumina structures where it was demonstrated that at high electric fields (i.e., with high applied voltage), alumina nanoporous structures experienced strong "growth pressure" from all directions. ${ }^{30}$ Finally, this effect can generate the perfect hexagonal arrangement of nanotubular structures (or honey comb structures). This maximum ordering is typically observed for current conditions close to breakdown (burning). I.e., in this case a maximum HF concentration leads to a maximum field, resulting in maximum ordering (up to a point where film breakdown or dissolution dominates).

In addition, the concentration of $\mathrm{HF}$ affects the tube diameter which is shown in Figure 3f. As the HF concentration increases, the diameters of nanotubes decrease from $140 \mathrm{~nm}(0.2 \mathrm{M})$ to $52 \mathrm{~nm}(5 \mathrm{M})$, and the homogeneity of diameter is improved when the nanotubes are prepared in a highly concentrated HF solution; i.e. the size difference is reduced from $\pm 10 \mathrm{~nm}$ (low concentration of HF: $0.2 \mathrm{M}$ ) to $\pm 2 \mathrm{~nm}$ (high concentration of HF: $5 \mathrm{M}$ ). Consequently, a concentration of $3 \mathrm{M} \mathrm{HF}$ was chosen for obtaining ideally ordered U-tubes. 

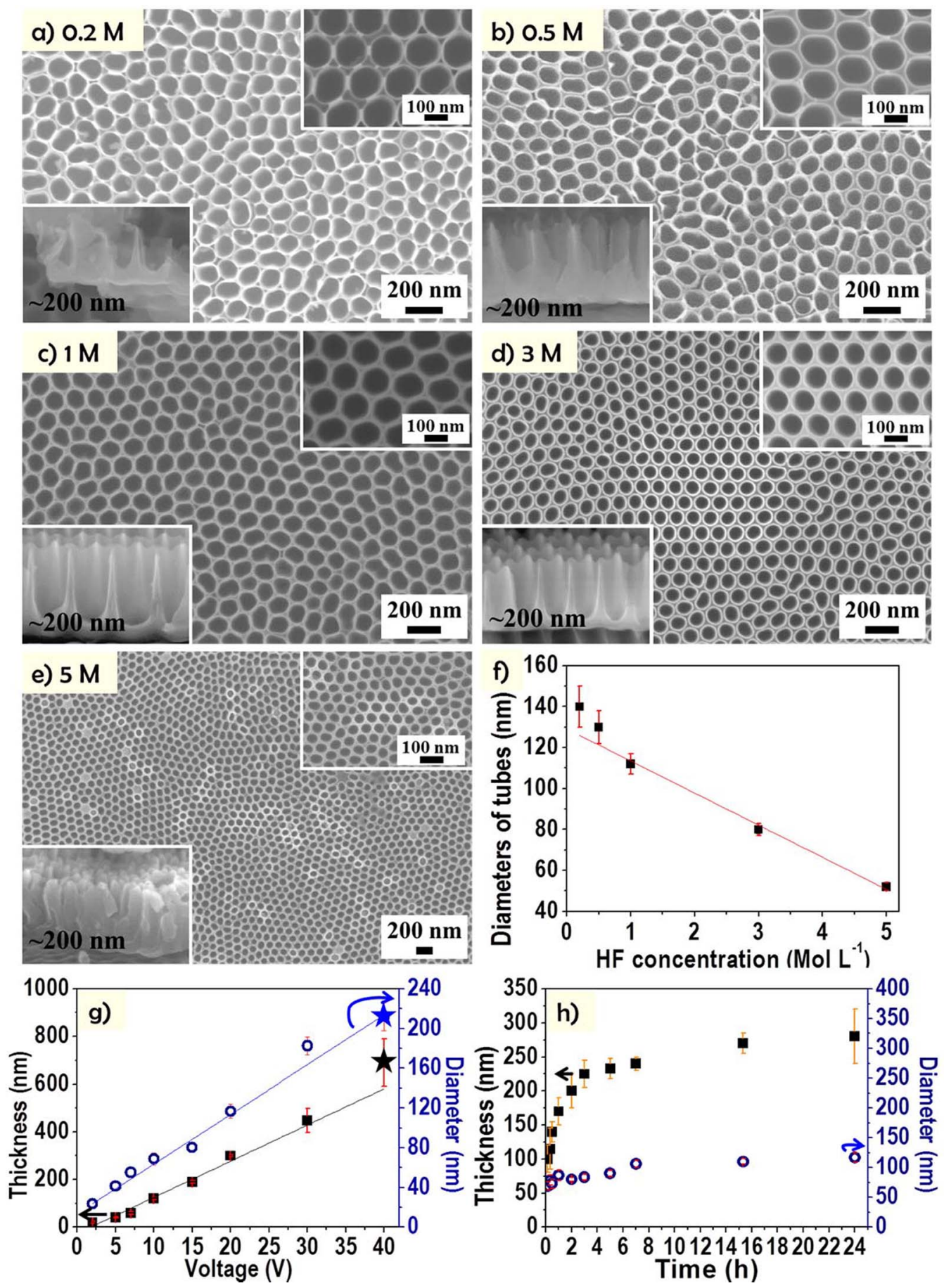

Figure 3. a e) SEM images of anodic $\mathrm{TiO}_{2} \mathrm{NTs}$ grown in different concentrations of $\mathrm{HF}$ in $\mathrm{o}-\mathrm{H}_{3} \mathrm{PO}_{4}$ solution at $15 \mathrm{~V}$ and $100^{\circ} \mathrm{C}$ for $2 \mathrm{~h}$. f) Tube diameter as a function of the HF concentration. g) Effect of the applied voltage on thickness and diameter of tubes anodized for $2 \mathrm{~h}$ (污 marks a T of $80^{\circ} \mathrm{C}$ ). $\mathrm{h}$ ) Effect of the anodizing time on thickness and diameter of tubes.

The diameter and length of the nanotubes were also studied as a function of the applied voltage. Figure $3 \mathrm{~g}$ and Figures $4 \mathrm{a} \sim 4 \mathrm{~d}$ show a linearly increasing diameter and tube length with increasing voltage. A minimal diameter and length of the $\mathrm{TiO}_{2}$ nanotubes were obtained at $2 \mathrm{~V}(\mathrm{D} \sim 22 \mathrm{~nm}, \mathrm{~L} \sim 20 \mathrm{~nm})$, and the maximum values were observed at $40 \mathrm{~V}(\mathrm{D} \sim 220 \mathrm{~nm}, \mathrm{~L} \sim 700 \mathrm{~nm})$. As shown in Figure $3 \mathrm{~g}$ and Figures $4 \mathrm{a} \sim 4 \mathrm{~d}$, the voltages could only be varied successfully in a range from 2 to $40 \mathrm{~V}$ (at $100^{\circ} \mathrm{C}$ for $2-30 \mathrm{~V}$ or at 80 or $90^{\circ} \mathrm{C}$ up to $40 \mathrm{~V}$ ). For higher voltages (e.g. $50 \mathrm{~V})$, strong bubble formation occurred and the current density rapidly increased as typical for breakdown conditions (burning). Furthermore, Figure S1 shows that if the electrolytes were kept below $80^{\circ} \mathrm{C}$, non-homogenous structures were formed and not the ideal round shaped bottoms of the nanotubular structures were obtained. In contrast, by maintaining the temperature at $90^{\circ} \mathrm{C}$ and above, the homogeneity of the tube arrays and the shapes of the tube tops were evidently improved (Figure 4d). Clearly, in this electrolyte the anodizing temperature is one of the crucial factors in forming highly ordered $\mathrm{TiO}_{2}$ nanotube arrays. As evident from the SEM images in Figure S2, well organized $\mathrm{TiO}_{2}$ nanotubes could be formed only at high temperatures (over $80^{\circ} \mathrm{C}$ ). Furthermore, among the various high temperatures $\left(80,100\right.$ and $\left.120^{\circ} \mathrm{C}\right)$, the $\mathrm{TiO}_{2}$ nanotubes prepared at $100^{\circ} \mathrm{C}$ show the highest homogeneity over the entire arrays (Figure 1c). Anodizing 

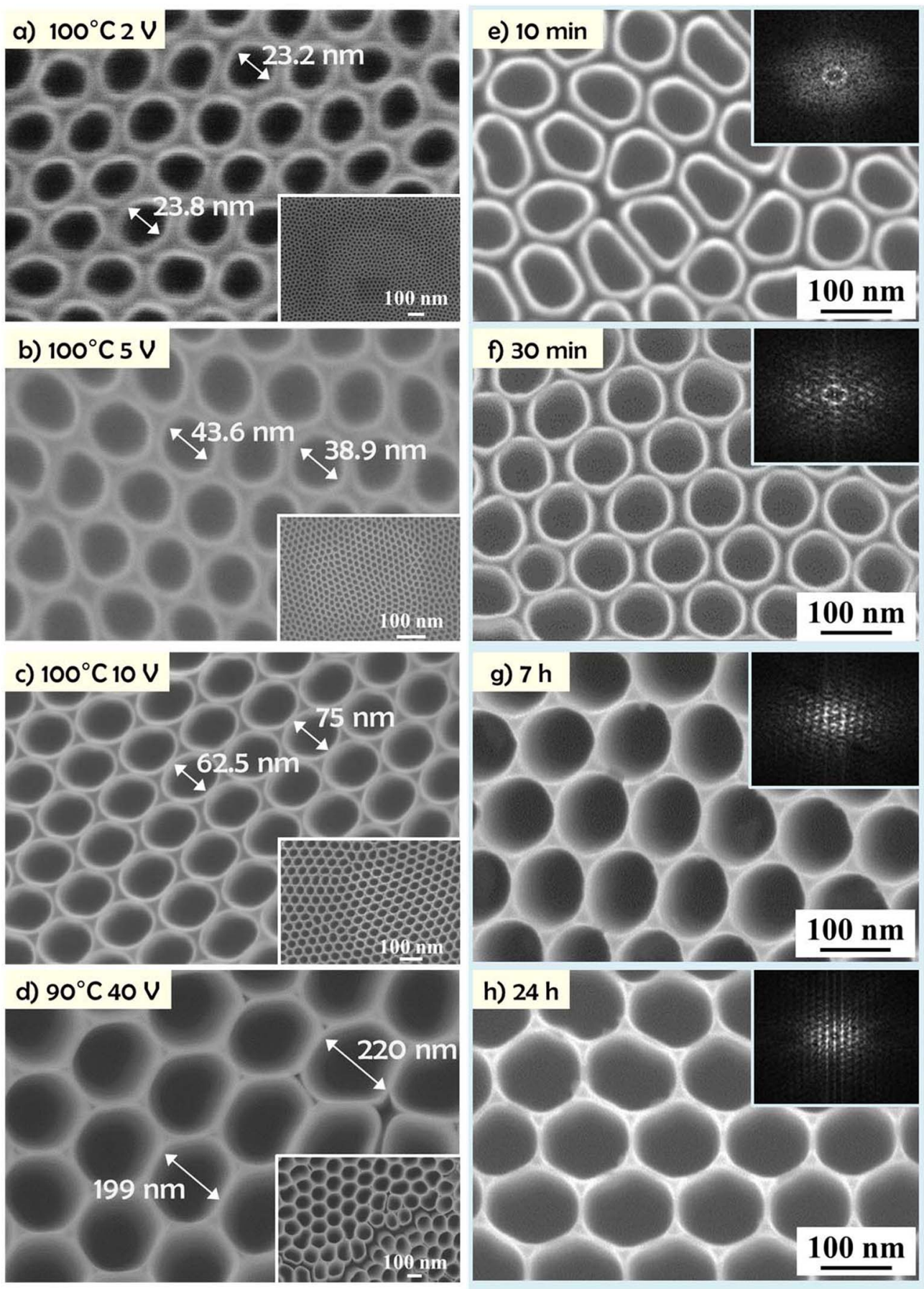

Figure 4. SEM images of anodic $\mathrm{TiO}_{2} \mathrm{NTs}$ anodized in $3 \mathrm{M} \mathrm{HF} / \mathrm{H}_{3} \mathrm{PO}_{4}$ at $100^{\circ} \mathrm{C}$ for $2 \mathrm{~h}$ at different potentials: a) $2 \mathrm{~V}$, b) $5 \mathrm{~V}$, c) $10 \mathrm{~V}$ and d) $40 \mathrm{~V}$. At the applied potential of $40 \mathrm{~V}$ a temperature of $100^{\circ} \mathrm{C}$ could not be applied, due to decomposition of the electrolyte accompanied by gas evolution. e $\mathrm{h}$ ) SEM images and FFT images of anodic $\mathrm{TiO}_{2} \mathrm{NTs}$ in $3 \mathrm{M} \mathrm{HF} / \mathrm{H}_{3} \mathrm{PO}_{4}$ at $15 \mathrm{~V}$ and $100^{\circ} \mathrm{C}$ for different anodizing times: e) $\left.\left.\left.10 \mathrm{~min}, \mathrm{f}\right) 30 \mathrm{~min}, \mathrm{~g}\right) 7 \mathrm{~h}, \mathrm{~h}\right) 24 \mathrm{~h}$.

at other temperatures leads to etched morphologies $\left(120^{\circ} \mathrm{C}\right)$ or to an inhomogeneous morphology of the nanotube layers $\left(80^{\circ} \mathrm{C}\right)$. At room temperature, the $\mathrm{TiO}_{2}$ structures consist of small dimples with a depth of only $\sim 40 \mathrm{~nm}$. The arrays are not homogenous and some tube tops are closed. The key effect of temperature in this electrolyte is to adjust the $\mathrm{H}_{2} \mathrm{O}$ content in $\mathrm{H}_{3} \mathrm{PO}_{4}$.

Figure $3 \mathrm{~h}$ shows the effect of anodization time on the length of the nanotubes. The growth rate of anodic $\mathrm{TiO}_{2} \mathrm{NTs}$ is relatively fast up to 3 hours, but after a length of $230 \mathrm{~nm}$ is reached, the growth rate slightly decreases reaching a steady state, i.e. growth and dissolution are in equilibrium. This is related to high-field controlled growth and dissolution of the $\mathrm{TiO}_{2}$ nanotubes. ${ }^{29,31}$ The critical parameters of the growth rate are the $\mathrm{O}$-ion mobility and $\mathrm{Ti}^{4+}$ migration in the tube bottom $\mathrm{TiO}_{2}$ layer at fixed applied potential. A thicker or better quality tube bottom limits the $\mathrm{O}$-ion and $\mathrm{Ti}^{4+}$ movement through the bottom layer, hence the tube growth is slower than at the beginning of anodization, in the present case this may be described to chemical changes at the tube bottom. ${ }^{6}$ Please note that as dissolution of the $\mathrm{TiO}_{2}$ surface into the electrolyte continues, the thickness is kept at around $250 \mathrm{~nm}$, but the $\mathrm{TiO}_{2}$ NTs show very thin and sharp edges.

Figures $4 \mathrm{e} \sim 4 \mathrm{~h}$ shows the impact of the anodizing time on the diameter and the ordering of the U-tube arrays. The SEM top views 

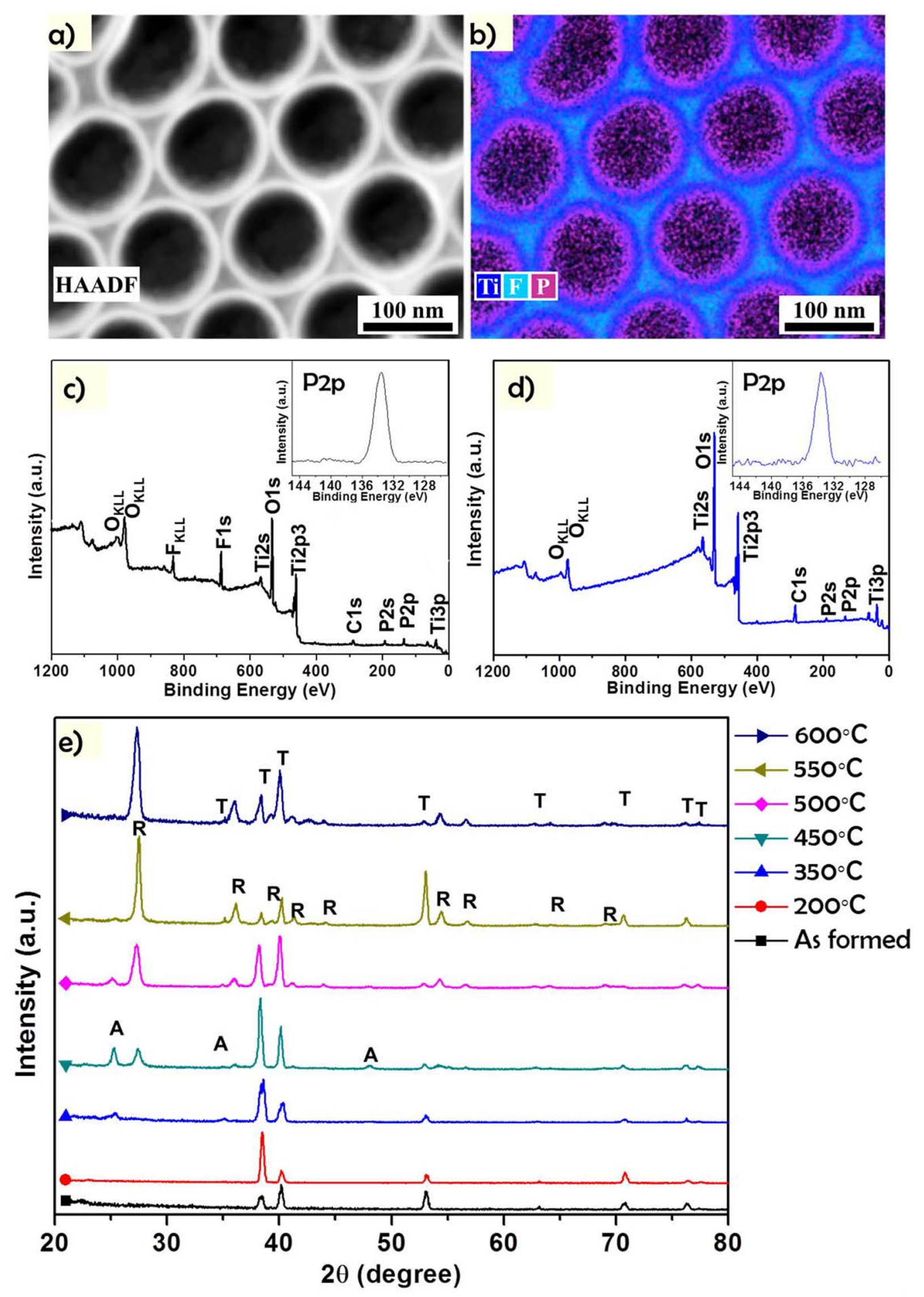

Figure 5. a) TEM HAADF image, b) elemental mapping (TEM-EDS) of U-tubes before annealing. XPS and HR-XPS for highly ordered TiO $\mathrm{N}_{2} \mathrm{NTs}_{\mathrm{c}}$ ) as-formed (U-tubes in $3 \mathrm{M} \mathrm{HF} / \mathrm{H}_{3} \mathrm{PO}_{4}$ at $100^{\circ} \mathrm{C}$ and $15 \mathrm{~V}$ for $2 \mathrm{~h}$ ), and d) after annealing at $450^{\circ} \mathrm{C}$ for $1 \mathrm{~h}$ in air. e) XRD patterns of the U-tubes after heat-treatment in air for $1 \mathrm{~h}$ at different temperatures (A - anatase, $\mathrm{R}$ - Rutile, $\mathrm{T}$ - Titanium).

show a clear transition to more connected morphologies and better aligned nanotubes with time, while the thickness stagnates after ca. $7 \mathrm{~h}$ of anodization (Figure $3 \mathrm{~h}$ ). The insets in Figures $4 \mathrm{e} \sim 4 \mathrm{~h}$ clearly illustrate that the degree of ordering is increased with increasing anodization time (leading to drastic changes in the FFT data). In case of anodization for $2 \mathrm{~h}$, the alignment is achieved in essentially perfect shape and the degree of ordering is not significantly changed any further for longer times.
Figures 5a $5 \mathrm{~b}$ shows TEM HAADF image and an elemental mapped (TEM-EDS) of the as-formed U-tubes through the entire $200 \mathrm{~nm}$ thick layer that was peeled off from the surface. The elemental map clearly shows a phosphorous-rich layer on the inside of the cavities and a fluoride-rich layer on the outside of the tube walls. This is in line with XPS results (Figures 5c,5d) that confirm the presence of these elements in the as formed tubes. The high resolution $\mathrm{P} 2 \mathrm{p}$ peak is at a position of $133.2 \mathrm{eV}$ that can be assigned to a $\mathrm{P}-\mathrm{O}$ 

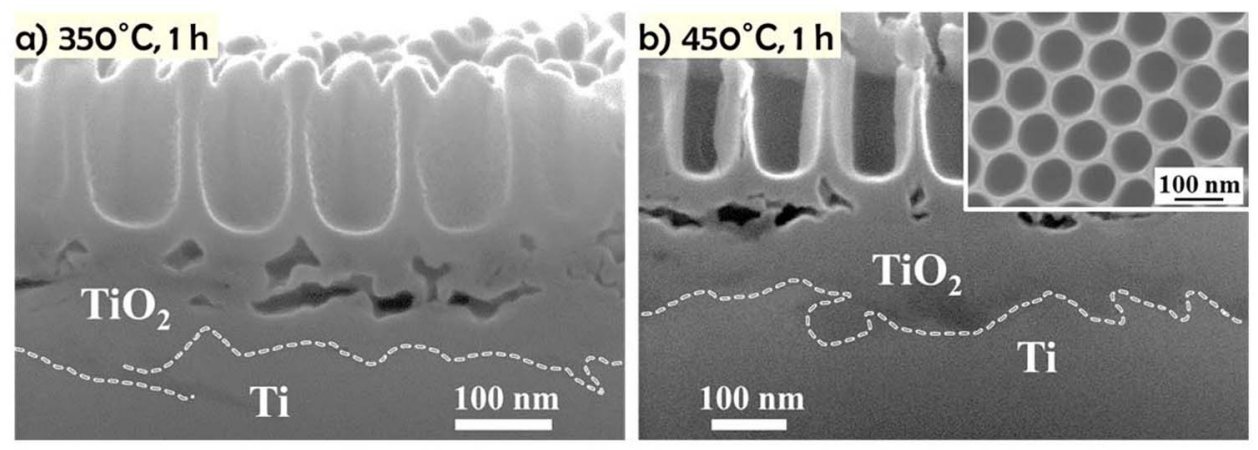

c)

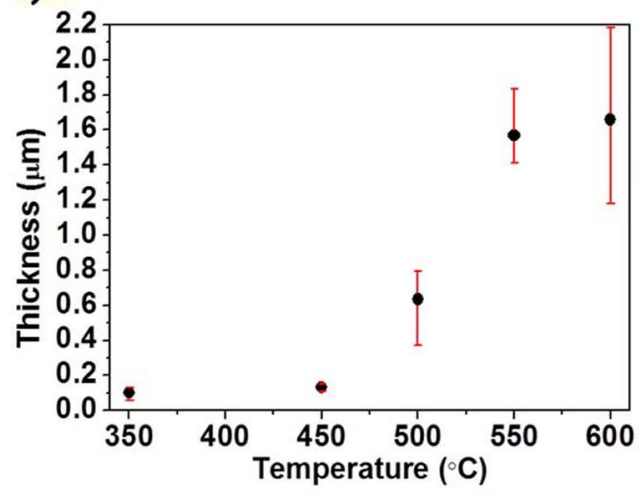

d)

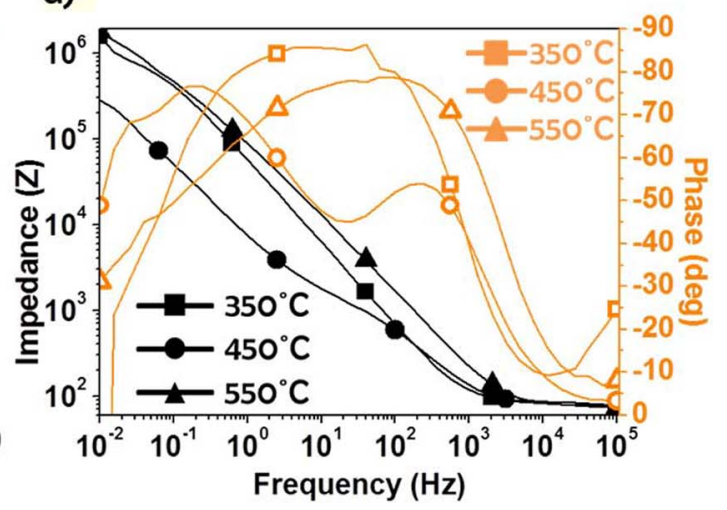

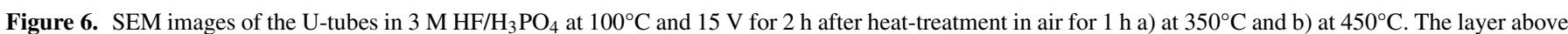

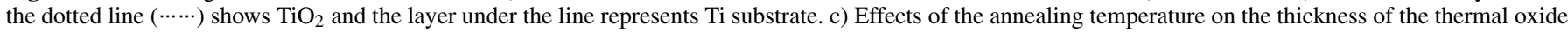
layer. d) Bode plot for U-tubes after heat-treatment at different temperatures in air for $1 \mathrm{~h}$.

bond as in phosphates. ${ }^{32,33}$ Figure 5 d illustrates that this phosphate layer is stable after annealing at $450^{\circ} \mathrm{C}$. The formation of fluoride-rich layers at the bottom of the tubes (between the Ti-metal and the oxide) has been previously observed and discussed for other titania tubes grown in fluoride electrolytes (literature describes this as a result of a high field transport of $\mathrm{F}^{-}$in competition to $\mathrm{O}^{2-}$ through the growing oxide) ${ }^{34,35}$ However, the formation of a uniform inner wall coating of the nanotubes with phosphate-species is unique to the here introduced electrolyte.

XRD patterns in Figure 5e show the as grown tubes to be amorphous. Figure 5e moreover shows the XRD patterns for tubes annealed at different temperatures, and Figures $6 a \sim 6 b$, Figure S3 show corresponding SEM images. After annealing at different temperatures, it is apparent that anatase phase (peak position at $25.3^{\circ}$ ) appears at an annealing temperature of $350^{\circ} \mathrm{C}$ and rutile phase $\left(27.5^{\circ}\right)$ at a temperature of $450^{\circ} \mathrm{C}$. From XPS (Figure $5 \mathrm{~d}$ ), after annealing at $450^{\circ} \mathrm{C}$ clearly the fluoride peak is largely lost (in line with literature), ${ }^{9,20}$ however, the phosphate-peak is still present, similar to as-formed tubes (Figure $5 \mathrm{c}$ ).

From XRD, the peak intensity of rutile increases steadily with temperature, at temperatures of $450^{\circ} \mathrm{C}$, the anatase and rutile peaks show similar intensities. For higher temperatures, the XRD oxide response becomes dominated by rutile. However, the origin of rutile is not primarily due to a phase conversion of the tubes. Namely, SEM images in Figures $6 \mathrm{a} \sim 6 \mathrm{~b}$ show top and cross-sectional images (ion milled crosssections) of heat-treated $\mathrm{TiO}_{2}$ NTs. The white dotted lines $(\cdots)$ in the images represent the boundaries of $\mathrm{Ti}$ metal and $\mathrm{TiO}_{2}$. Evidently thermal oxide is formed from the Ti metal substrate, and the thickness of these oxide layers can increase up to $1.5 \mu \mathrm{m}$ with increasing annealing temperature (Figure $6 \mathrm{c}$ ).$^{20,21}$

Comparing XRD (Figure 5e) and SEM (Figures 6a $6 \mathrm{~b}$, Figure S3), it can be deduced that the thick thermal oxide layers consist of rutile. This is in line with literature ${ }^{20}$ that shows Ti to be preferentially oxidized to rutile (rather than anatase) when annealed under $\mathrm{O}_{2}$ containing conditions. The growth of the rutile layers spoils the nanotube arrays by invading rutile into the anatase nanotube structures (inserts in Figure S3). This growing behavior of rutile layers from the Ti metal for highly ordered $\mathrm{TiO}_{2}$ NTs is in line with earlier literature which reports that the rutile phase is firstly grown at the metal/ $/ \mathrm{TiO}_{2}$ interface and then proceeds up the tube walls and toward the tube tops (with higher annealing temperatures or longer thermal treatments). ${ }^{20,21,36}$

In view of the use of the nanotubes as electrodes (or photoelectrodes), the differently annealed $\mathrm{TiO}_{2}$ NT layers were tested with electrochemical impedance spectroscopy (EIS). According to Figure 6d, the $\mathrm{TiO}_{2} \mathrm{NT}$ layers heat-treated at $450^{\circ} \mathrm{C}$ (a mixture of anatase and rutile) show the lowest overall impedance and the lowest charge transfer resistance among the differently annealed nanotubes, while a significantly higher impedance is observed for NTs annealed at $550^{\circ} \mathrm{C}$, due to the large amount of rutile (anatase is reported to have significantly higher conductivity than rutile). ${ }^{36,37}$ Noteworthy, $\mathrm{TiO}_{2} \mathrm{NTs}$ annealed at $350^{\circ} \mathrm{C}$ (no rutile peaks in Figure 5e) show also a very high resistance, as still a high amount of amorphous phase (low conductivity) is present in the $\mathrm{TiO}_{2}$ NTs.

To enable the use of these highly organized $\mathrm{TiO}_{2} \mathrm{NTs}$ for various applications, a higher aspect ratio of the tubes is desired. However, as the electrolyte used here (concentrated $\mathrm{H}_{3} \mathrm{PO}_{4} / \mathrm{HF}$ at $\sim 100^{\circ} \mathrm{C}$ ) is strongly etching the formed tubes, in a one-step process only a limited tube length of $(\sim 300 \mathrm{~nm})$ is achievable (see Figure 3$)$. Therefore we explored a two step-anodization treatment.

Two-step anodization techniques have been used for growing wellaligned nanotube arrays with open top surfaces. ${ }^{38}$ In the conventional approach, during the first anodization step, a $\mathrm{TiO}_{2}$ nanotube layer with a relatively large thickness is needed (to be able to remove it by sonication) - then the underlying texture of substrate (a highly arranged dimple structure) is used as a template for the second step of $\mathrm{TiO}_{2}$ nanotube growth. However, in the case of the here presented U-tubes, the elimination of the first layer is not necessary, since the arrangement of $\mathrm{TiO}_{2} \mathrm{NTs}$ is already nearly perfect and the thickness of the layer and properties of the layer allow to directly form the second layer. In the second anodization step, the bottoms of the nanotubes act as new nanotube growth initiation points. As the anodization proceeds, the 

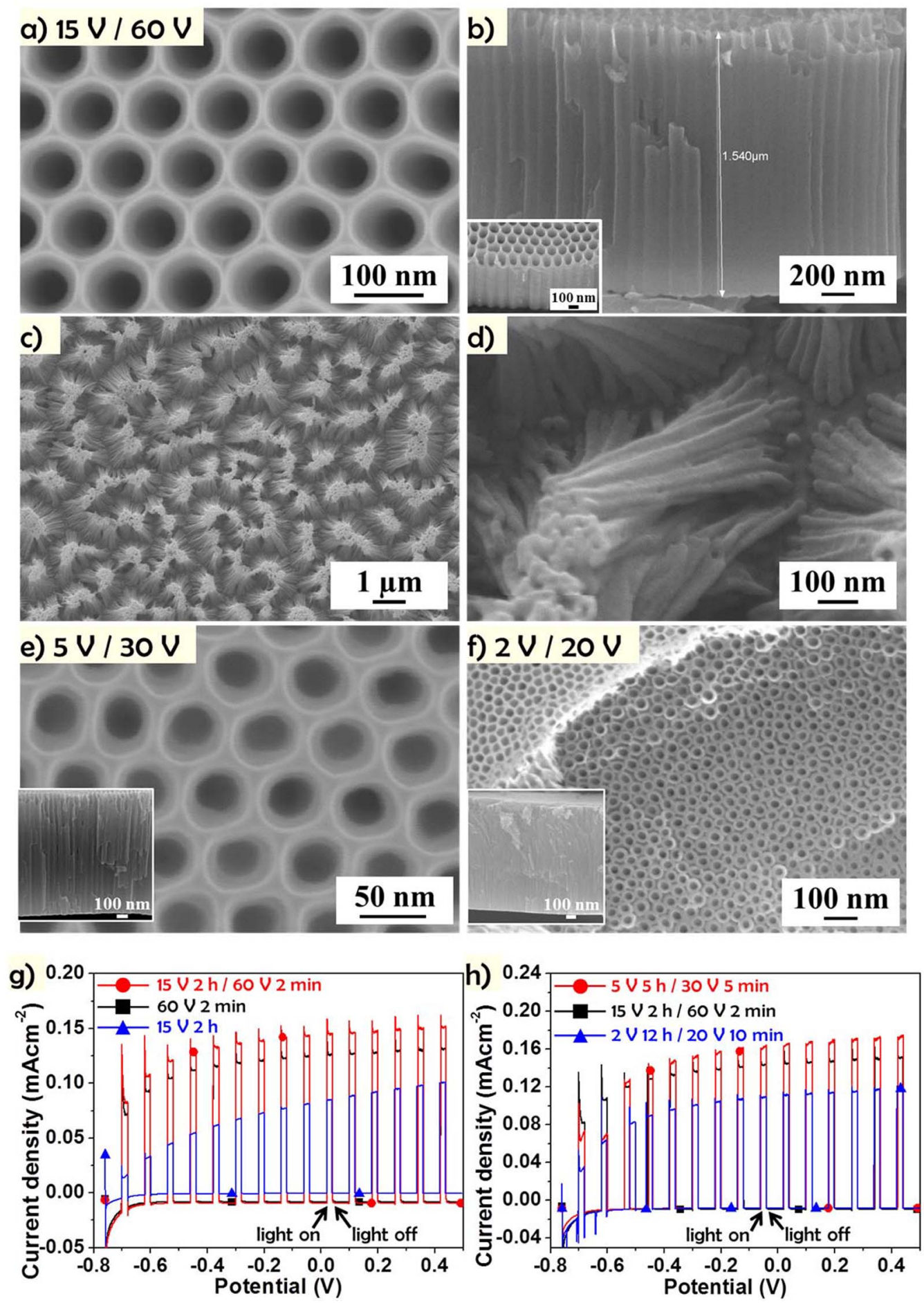

Figure 7. SEM images of; a b) double anodized $\mathrm{TiO}_{2} \mathrm{NTs}$ under optimized conditions (at $15 \mathrm{~V}$ in $\mathrm{HF}_{3} / \mathrm{H}_{3} \mathrm{PO}_{4}$ at $100^{\circ} \mathrm{C}$ for $2 \mathrm{~h} / /$ at $60 \mathrm{~V}$ in $\mathrm{NH} / \mathrm{F} / \mathrm{EG}$ at $\mathrm{RT}$ for $2 \mathrm{~min}$ ); $\mathrm{c} \sim \mathrm{d}$ ) A polystyrene replica structure of the tubes of Figure $7 \mathrm{a} \sim \mathrm{b}$. SEM images of double anodized $\mathrm{TiO}_{2} \mathrm{NTs}$ e) at $5 \mathrm{~V}$ in $\mathrm{HF}_{3} \mathrm{H}_{3} \mathrm{PO} \mathrm{for} 5 \mathrm{~h}, / / 30 \mathrm{~V}$ in $\mathrm{NH}_{4} \mathrm{~F} / \mathrm{EG}$ for $5 \mathrm{~min}$; and $\mathrm{f}$ ) at $2 \mathrm{~V}$ in $\mathrm{HF} / \mathrm{H}_{3} \mathrm{PO}_{4}$ for $12 \mathrm{~h} / / 20 \mathrm{~V}$ in $\mathrm{NH}_{4} \mathrm{~F} / \mathrm{EG}$ for $10 \mathrm{~min}$. Photocurrent measurements of double anodized TiO 2 NTs: g) comparison of double anodized nanotubes with single anodized nanotubes, $\mathrm{h}$ ) comparison of different optimized double anodized nanotubes.

bottom becomes thinner and then eventually the tubes develop open bottom-structures with a connection between the first layer and the second layer (as shown in Figures 7a 7f).

Figures $7 \mathrm{a} \sim 7 \mathrm{~b}$ show a top-view and a cross-sectional image of the nanotubes after double anodization. The first anodization was carried out as described above at $15 \mathrm{~V}$ and $100^{\circ} \mathrm{C}$ for $2 \mathrm{~h}$ in the $\mathrm{HF} / \mathrm{H}_{3} \mathrm{PO}_{4}$ electrolyte; the second anodization was performed at $60 \mathrm{~V}$ and room temperature for $2 \mathrm{~min}$ in ethylene glycol (EG) based $\mathrm{NH}_{4} \mathrm{~F}$ solution.
This results in a match of the two structures in diameters and registry. The structures are extremely well organized, and in addition lengths controllable between $200 \mathrm{~nm}$ to $1.5 \mu \mathrm{m}$ can be achieved. In order to demonstrate the all open structure between upper and lower tube part we fabricated polystyrene (PS) replica from the nanotubular structures (see Figures 7a 7b). These PS replica (Figures 7c $\sim 7 d$ ) structures were prepared by dropping molten polystyrene into the nanotubes and then dissolving the $\mathrm{TiO}_{2}$ NT layers by HF solution (the PS 
structures bundle together due to electrostatic force while they are dried by $\mathrm{N}_{2}$ gas.). These structures evidently show that the second nanotube layers do perfectly match with the first nanotube layer. It should be noted that in classic 2-step processes (in the same electrolyte), the applied potential for both layers is similar, as the diameters of the first layer match that of the underneath tube layer. However, in our case the second electrolyte $\left(\mathrm{NH}_{4} \mathrm{~F} / \mathrm{EG}\right)$ is different from the first electrolyte $\left(\mathrm{HF} / \mathrm{H}_{3} \mathrm{PO}_{4}\right)$. Therefore, to reach a match between the upper and the lower layer, the anodization voltage needs to be adjusted. This is illustrated in a second example: Figure 7e shows well-organized double anodized $\mathrm{TiO}_{2}$ nanotubes where the first layer was prepared at $5 \mathrm{~V}$ for $5 \mathrm{~h}$ in the $\mathrm{HF} / \mathrm{H}_{3} \mathrm{PO}_{4}$ electrolyte. To match this, the second layer grown in $\mathrm{NH}_{4} \mathrm{~F} / \mathrm{EG}$ had to be grown at $30 \mathrm{~V}$ for $5 \mathrm{~min}$. Figure $7 \mathrm{f}$ shows relatively small diameter $(\sim 25 \mathrm{~nm})$ tubes which were grown at $2 \mathrm{~V}$ in the first anodization, and $20 \mathrm{~V}$ was employed in the second step, resulting in highly ordered $\mathrm{TiO}_{2}$ NTs with small diameters which were grown to a length of up to $1.2 \mu \mathrm{m}$. Above examples show that by this approach highly ordered nanocavities can be extended to highly ordered nanotube layers. Using this approach allows, as shown in Figure 7, to grow these ordered nanotubes of the same length but with a variable diameter.

In order to demonstrate the benefit of tube extension and control over diameter and length, we carried out photoelectrochemical potential sweep measurements (under solar light - AM 1.5) for i) double anodized samples versus single anodized samples (Figure $7 \mathrm{~g}$ ), and ii) double anodized samples with a length of $1.2 \mu \mathrm{m}$ and different diameters (Figure 7h). The photocurrent obviously increases with the tube length, since the light absorption and the active surface area are much higher than for shorter tubes (Figure $7 \mathrm{~g}$ ). By comparing the photocurrent results of "60 V 2 min" (classic nanotubes) and " $15 \mathrm{~V} 2 \mathrm{~h}$ // $60 \mathrm{~V} 2$ min" (highly ordered nanotubes), it is noticed that although the tubes have an identical geometry, the arrangement of $\mathrm{TiO}_{2} \mathrm{NTs}$ is indeed affecting the photoresponse: well aligned nanotube structures enhanced the photocurrent from 0.125 to $0.15 \mathrm{~mA} \mathrm{~cm}^{-2}$ at $0.5 \mathrm{~V}$.

Figure $7 \mathrm{~h}$ shows the photocurrent measurements with double anodized $\mathrm{TiO}_{2}$ NT layers grown under optimized conditions. The thicknesses of all nanotube layers are around $1.2 \mu \mathrm{m}$, but the diameters of the nanotubes are different, i.e. " $2 \mathrm{~V} / / 20 \mathrm{~V}$ ": $\sim 25 \mathrm{~nm}, " 5 \mathrm{~V} / /$ $30 \mathrm{~V} ": \sim 40 \mathrm{~nm}$ and " $15 \mathrm{~V} / / 60 \mathrm{~V} ": \sim 80 \mathrm{~nm}$. From the considerable amount of literature regarding high aspect ratio $\mathrm{TiO}_{2} \mathrm{NTs},{ }^{9,17,31}$ it was assumed that the highest aspect ratio (" $2 \mathrm{~V} / / 20 \mathrm{~V}$ ", aspect ratio $\geq 48$ ) - that is the smallest diameter - would lead to the highest efficiency of the light response under solar light, yet the sample of " $5 \mathrm{~V} / / 30 \mathrm{~V}$ " (aspect ratio $\geq 30$ ) shows the highest current density $\left(0.175 \mathrm{~mA} \mathrm{~cm}^{-2}\right)$ at $0.5 \mathrm{~V}$, which is a higher value than the photocurrent density from the sample of " $15 \mathrm{~V} / / 60 \mathrm{~V}$ " (aspect ratio $\geq 15$ ). This may indicate that at small tube diameters the advantages of directional carrier transport in nanotubes ${ }^{31}$ are increasingly lost as carrier transport becomes increasingly likely in the lateral direction (such as in nanoparticulate layers).

This example illustrates that a precise control over order, length and diameter of $\mathrm{TiO}_{2}$ nanotubes is essential to fine-tune the optimum electrochemical response. Moreover, with the highly ordered cavities presented here, as well as their use to trigger highly ordered highaspect ratio nanotube arrays, a wide number of direct applications in photoelectrochemistry, photocatalysis, and electrochemistry become possible. Additionally, indirect uses such as templating secondary material with an extremely high precision and order becomes feasible.

\section{Conclusions}

In the present work we investigated the formation of extremely well-organized $\mathrm{TiO}_{2}$ nanostructures (nanotubes) by anodizing $\mathrm{Ti}$ foils under drastic conditions $\left(\mathrm{HF} / \mathrm{H}_{3} \mathrm{PO}_{4}\right.$ containing electrolytes). Through the examination of a broad range of electrochemical conditions, such as electrolyte composition, temperature, anodizing time (related to the length of tubes), and applied voltage (related to the diameter of tubes), we established optimized conditions for highly ordered $\mathrm{TiO}_{2} \mathrm{NTs}_{\mathrm{N}}$ with open top and a U-shape combined with a smooth wall. We describe and discuss tools to control tube geometry and order.
We show that heat-treatments of the short aspect ratio, amorphous U-tubes, lead to anatase and rutile formation (as characterized by XRD), with a ratio that depends strongly on the annealing temperature. In fact, thick thermal rutile layers are formed under the nanotube layers at higher temperatures. These variations lead to strong alterations in electrical and photochemical properties.

To overcome the drawbacks of the short aspect ratio, we introduced a double anodization strategy to extend the length of $\mathrm{TiO}_{2}$ nanotubes. Both short and extended tubes formed in the concentrated $\mathrm{H}_{3} \mathrm{PO}_{4}$ electrolytes lead to extremely highly ordered geometries and a high level of control over length and diameter that can be exploited to optimize the electrochemical and photoelectrochemical properties of $\mathrm{TiO}_{2}$ nanotube layers

\section{Acknowledgments}

Patrik Schmuki thank Hugh Isaacs for many inspiring discussions on titanium anodizing (and other topics). The financial support from ERC and DFG within the framework of its Excellence Initiative for the Cluster of Excellence "Engineering of Advanced Materials" is thankfully acknowledged. We thank M. Altomare, A. Naldoni, and O. Tomanec for providing the TEM investigations in Figures 5a, $5 \mathrm{~b}$.

\section{ORCID}

\section{J. E. Yoo (10) https://orcid.org/0000-0002-7923-3100}

P. Schmuki (1) https://orcid.org/0000-0002-9208-5771

\section{References}

1. T. Kasuga, M. Hiramatsu, A. Hoson, T. Sekino, and K. Niihara, Langmuir, 14, 3160 (1998).

2. M. S. Sander, M. J. Côté, W. Gu, B. M. Kile, and C. P. Tripp, Adv. Mater., 16, 2052 (2004).

3. T. Kasuga, M. Hiramatsu, A. Hoson, T. Sekino, and K. Niihara, Adv. Mater, 11, 1307 (1999).

4. Y. Suzuki and S. Yoshikawa, J. Mater. Res., 19, 982 (2004).

5. Z. R. Tian, J. a. Voigt, J. Liu, B. McKenzie, and H. Xu, J. Am. Chem. Soc., 125, 12384 (2003).

6. J. M. Macak, H. Tsuchiya, A. Ghicov, K. Yasuda, R. Hahn, S. Bauer, and P. Schmuki, Curr. Opin. Solid State Mater. Sci., 11, 3 (2007).

7. Y. C. Nah, I. Paramasivam, and P. Schmuki, ChemPhysChem, 11, 2698 (2010).

8. P. Roy, D. Kim, K. Lee, E. Spiecker, and P. Schmuki, Nanoscale, 2, 45 (2010)

9. P. Roy, S. Berger, and P. Schmuki, Angew. Chemie - Int. Ed., 50, 2904 (2011)

10. S. Berger, R. Hahn, P. Roy, and P. Schmuki, Phys. Status Solidi Basic Res., 247, 2424 (2010).

11. P. Hoyer, Langmuir, 12, 1411 (1996).

12. B. O'Regan and M. Gratzel, Nature, 353, 737 (1991).

13. A. Fujishima and K. Honda, Nature, 238, 37 (1972).

14. M. Assefpour-Dezfuly, C. Vlachos, and E. H. Andrews, J. Mater. Sci., 19, 3626 (1984).

15. J. M. Macák, H. Tsuchiya, and P. Schmuki, Angew. Chemie - Int. Ed., 44, 2100 (2005)

16. J. M. Macak, H. Tsuchiya, L. Taveira, S. Aldabergerova, and P. Schmuki, Angew. Chemie - Int. Ed., 44, 7463 (2005).

17. S. P. Albu, A. Ghicov, J. M. Macak, and P. Schmuki, Phys. Status Solidi - Rapid Res. Lett., 1, 65 (2007)

18. F. Keller, M. S. Hunter, and D. L. Robinson, J. Electrochem. Soc., 100, 411 (1953).

19. H. Masuda and K. Fukuda, Science, 268, 1466 (1995).

20. S. P. Albu, A. Ghicov, S. Aldabergenova, P. Drechsel, D. LeClere, G. E. Thompson, J. M. Macak, and P. Schmuki, Adv. Mater, 20, 4135 (2008).

21. S. P. Albu, H. Tsuchiya, S. Fujimoto, and P. Schmuki, Eur. J. Inorg. Chem., 4351 (2010).

22. S. So, F. Riboni, I. Hwang, D. Paul, J. Hammond, O. Tomanec, R. Zboril, D. R. Sadoway, and P. Schmuki, Electrochim. Acta, 231, 721 (2017).

23. S. So, I. Hwang, J. E. Yoo, S. Mohajernia, M. Mačković, E. Spiecker, G. Cha, A. Mazare, and P. Schmuki, Adv. Energy Mater, 8, 1800981 (2018).

24. T. Yanagishita, H. Inada, T. Kondo, N. T. Nguyen, P. Schmuki, and H. Masuda, $J$. Electrochem. Soc., 165, E763 (2018).

25. J. E. Yoo, K. Lee, M. Altomare, E. Selli, and P. Schmuki, Angew. Chemie - Int. Ed., 52, 7514 (2013)

26. J. E. Yoo, K. Lee, A. Tighineanu, and P. Schmuki, Electrochem. commun., 34, 177 (2013).

27. J. E. Yoo, K. Lee, and P. Schmuki, Electrochem. commun., 34, 351 (2013).

28. S. Leonardi, A. Li Bassi, V. Russo, F. Di Fonzo, O. Paschos, T. M. Murray, H. Efstathiadis, and J. Kunze, J. Phys. Chem. C, 116, 384 (2012).

29. R. Beranek, H. Hildebrand, and P. Schmuki, Electrochem. Solid-State Lett., 6, B12 (2003).

30. S. Ono, M. Saito, and H. Asoh, Electrochim. Acta, 51, 827 (2005) 
31. K. Lee, A. Mazare, and P. Schmuki, Chem. Rev., 114, 9385 (2014).

32. D. Briggs, Surf. Interface Anal.,3 (1981).

33. S. Krischok, C. Blank, M. Engel, R. Gutt, G. Ecke, J. Schawohl, L. Spies, F. Schrempel, G. Hildebrand, and K. Liefeith, Surf. Sci., 601, 3856 (2007).

34. S. Berger S. P. Albu, F. Schmidt-Stein, H. Hildebrand, P. Schmuki, J. S. Hammond, D. F. Paul, and S. Reichlmaier, Surf. Sci., 605, L57 (2011).
35. S. Mohajernia, A. Mazare, I. Hwang, S. Gaiaschi, P. Chapon, H. Hildebrand, and P. Schmuki, Appl. Surf. Sci., 442, 412 (2018).

36. A. Tighineanu, T. Ruff, S. Albu, R. Hahn, and P. Schmuki, Chem. Phys. Lett., 494 260 (2010).

37. S. So and P. Schmuki, Angew. Chemie - Int. Ed., 52, 7933 (2013),

38. G. Cha, K. Lee, J. E. Yoo, M. S. Killian, and P. Schmuki, Electrochim. Acta, 179, 423 (2015). 